\title{
Acute Effect of Gamma Irradiation on Gastric Acid Secretion and Gastric Mucosal Integrity in the Rat
}

\author{
Omar M.E. Abdel Salam ${ }^{1, \star}$, Ihsan Hadajat ${ }^{2}$, Ayman Ragab Bayomy ${ }^{1}$, Siham El- \\ Shinawy ${ }^{1}$, and Mahmoud S. Arbid ${ }^{1}$ \\ ${ }^{1}$ Department of Pharmacology, National Research Centre, Dokki, Cairo; ${ }^{2}$ Department of Biochemistry, \\ National Centre for Radiation Research and Technology, Cairo \\ E-mail: omasalam@hotmail.com
}

Received November 28, 2004; Revised February 20, 2005; Accepted February 22, 2005; Published March 18, 2005

The effect of 3- or 6-Gray (Gy) whole-body gamma irradiation on basal and stimulated gastric acid secretion was studied in pylorus-ligated rats. Different groups of rats were irradiated with a single 3- or 6-Gy fraction and examined 7 days after irradiation. Exposure to 3-Gy fraction led to marked increase in basal (nonstimulated) gastric acid output in the 4-h pylorus-ligated rat (47.5\% compared with unirradiated controls). After exposure to $6 \mathrm{~Gy}$, only $18.2 \%$ increase in gastric acid output was noted compared with unirradiated controls. Under pentagastrin or histamine stimulation, gastric acid secretion in those irradiated with 3- or 6-Gy fraction was markedly reduced compared to that of unirradiated controls. Exposure to 3- or 6-Gy gamma irradiation intensified the degree of gastric mucosal injury evoked by indomethacin or $50 \%$ ethanol in a dose-dependent manner. It is concluded that in the pylorus-ligated rat model, lower doses of gamma irradiation increase basal gastric acid secretion and impair the gastric mucosal barrier with marked increase in its permeability to $\mathrm{H}^{+}$following stimulation of acid secretion or exposure to barrier breakers. Exposure to irradiation is likely to result in failure of the parietal cell to respond to direct stimulation with histamine or pentagastrin.

KEYWORDS: whole-body gamma irradiation, gastric acid secretion, rats

\section{INTRODUCTION}

Very little information is available regarding the effect of ionizing irradiation on gastric acid secretion and the gastric mucosa. Exposure to ionizing irradiation can have profound effects on gastric function. In rats, acute erosive and ulcerative gastritis and atonic dilatation of the stomach followed localized $300-\mathrm{kV}$ $\mathrm{X}$-ray irradiation (28.5 Gy) of the stomach[1,2]. In man, therapeutic pelvic irradiation is associated with widespread, persistent changes in gastrointestinal function[3]. Studies in rats and guinea pigs indicated that exposure to irradiation could suppress gastric acid secretion[4,5,6]. More recently, however, Lehy et al.[7] reported an increase in gastric acid output and plasma gastrin levels in rats exposed to 2- or 6-Gy whole-body gamma radiation. In the present study, the effect of whole-body gamma irradiation with 3 or 6 Gy on basal and histamine- or pentagastrin-stimulated gastric acid secretion was examined. We also 
assessed the ability of the gastric mucosa of rats irradiated with 3- or 6-Gy gamma radiation to withstand noxious chemical challenge following $50 \%$ ethanol or indomethacin under such conditions.

\section{MATERIALS AND METHODS}

\section{Animals}

Sprague-Dawley strain rats, 120-130 g of body weight, were used throughout the study and housed under standardized conditions for light and temperature. Rats were randomly divided into different groups $(\mathrm{n}=$ 6-7 per group) and were irradiated with a single 3- or 6-Gy fraction for 15-20 min and examined for gastric acid secretion or gastric ulcer 7 days later. Irradiation was performed through the use of ${ }^{137} \mathrm{Cs}$ gamma rays from the gamma cell-40 belonging to the National Centre for Radiation Research and Technology (NCRRT). The dose rate was $1 \mathrm{~Gy} / 1.5 \mathrm{~min}$ at the time of the experiment. Rats were fasted for $18 \mathrm{~h}$ prior to experiments, but allowed water ad libitum, and kept in cages with wide meshed floors to prevent coprophagy.

\section{Study Design}

\section{Gastric Acid Secretion Studies}

The effects of whole-body irradiation on gastric acid secretion were studied in pylorus-ligated rats and compared to that in unirradiated rats. Pylorus ligation was done according to Shay et al.[8]. Briefly, rats were lightly anesthetized with ether, a midline laparatomy was done to expose the pylorus, and a silk ligature was tied around the pylorus; care being care taken not to interfere with the blood supply to the stomach and duodenum. The abdominal wall was then closed in layers with silk sutures. Rats were administered $2 \mathrm{ml}$ of physiological saline intragastrically (i.g.) through a soft orogastric tube. Rats were injected subcutaneously (s.c.) with $5 \mathrm{ml}$ saline to correct for possible dehydration during the experiment.

The effect of gamma irradiation on gastric acid secretion was studied under basal (unstimulated) conditions and after stimulation of gastric acid secretion with pentagastrin $(150 \mu \mathrm{g} / \mathrm{kg})$ or histamine (1 $\mathrm{mg} / \mathrm{kg}$ ). The stimulants of gastric secretion were injected s.c., immediately after pylorus ligation. Rats were killed $4 \mathrm{~h}$ after pylorus ligation, the esophagus was then ligated, stomachs excised, and gastric juice carefully collected in graduated tubes after removal of the esophageal ligature. The volume of gastric secretion was noted and gastric acid output determined by automatic titration to $\mathrm{pH} 7.0$ with $0.01 \mathrm{~N} \mathrm{NaOH}$ and $\mathrm{H}^{+}$output expressed as $\mu \mathrm{Eq} / 4 \mathrm{~h} / 100 \mathrm{~g}$.

\section{Gastric Ulcerogenic Studies}

The effects of indomethacin or ethanol on the gastric mucosa of rats irradiated with 3 or 6 Gy were studied and compared to that in control, unirradiated rats. Different groups of rats ( $n=6-7$ per group) were irradiated with a single 3- or 6-Gy fraction and examined 7 days after irradiation. Pylorus ligation was performed as described above, then gastric mucosal damage was evoked in pylorus-ligated rats by the administration of indomethacin (20 mg/kg s.c.) together with i.g. administration of $1 \mathrm{ml}$ of physiological saline or by i.g. ethanol of $1 \mathrm{ml}$ of $50 \%$ ethanol. Rats were injected with $5 \mathrm{ml}$ saline s.c. to correct for possible dehydration during the experiment. Rats were killed $4 \mathrm{~h}$ later.

\section{Assessment of Gastric Mucosal Injury}


Stomachs were opened along the greater curvature, rinsed with saline, extended on a plastic board, and examined for mucosal lesions. The number and severity of mucosal lesions were noted and lesions were scaled as follows: petechial lesions $=1$, lesions less than $1 \mathrm{~mm}=2$, lesions between 1 and $2 \mathrm{~mm}=3$, lesions between 2 and $4 \mathrm{~mm}=4$, and lesions more than $4 \mathrm{~mm}=5$. A total lesion score for each animal is calculated as the total number of lesions multiplied by the respective severity scores. Results are expressed as the severity of lesions/rat[9].

\section{Histology}

For histologic assessment, the stomachs were pinned flat on cardboard and immersed in $10 \%$ formalin solution and later embedded in paraffin. From the paraffin-embedded tissue blocks, hematoxylin and eosin-stained sections were coded. Sections were evaluated qualitatively under light microscopy.

\section{Determination of Gastric Mucus Content}

Adherent gastric mucus was determined by the alcian blue recovery technique according to the method of Corne et al.[10]. Gastric mucus was expressed as $\mu \mathrm{g} / \mathrm{g}$ wet tissue.

\section{Determination of Gastric Acid Secretion}

In ulcer studies, after rats have been killed, the esophagus was ligated, stomachs excised, and gastric juice carefully collected in graduated tubes after removal of the esophageal ligature. The volume of gastric secretion was noted and gastric acid output determined by automatic titration to $\mathrm{pH} 7.0$ with $0.01 \mathrm{~N} \mathrm{NaOH}$ and $\mathrm{H}^{+}$output expressed as $\mu \mathrm{Eq} / 4 \mathrm{~h}$.

\section{Drugs and Chemicals}

Pentagastrin (Peptavlon, ICI, U.K.), histamine dihydrochloride (BDH Chemicals, U.K.), indomethacin (Kahira Pharm \& Chem. Ind. Co., Egypt), urethane (Sigma, U.S.), and alcian blue 8 GX (Sigma, U.S.) were used. Drugs were freshly dissolved with isotonic $\mathrm{NaCl}$ immediately before the experiments to obtain the necessary doses. Indomethacin was dissolved in 5\% sodium bicarbonate solution.

\section{Statistical Analysis}

Results were expressed as means \pm SEM. Data were analyzed using one-way analysis of variance; $p$ values less than 0.05 were considered as significant.

\section{RESULTS}

\section{Gastric Acid Secretion Studies}

\section{Basal Gastric Acid Secretion}

Basal gastric acid secretion in unirradiated control rats was $278.3 \pm 12.9 \mu \mathrm{Eq} / 100 \mathrm{~g} / 4 \mathrm{~h}$ after ligating the pylorus. Exposure to 3- or 6-Gy gamma irradiation led to significant increase in basal (nonstimulated) gastric acid secretion in the 4-h pylorus-ligated rat. The increase in $\mathrm{H}^{+}$output was most marked in those 
irradiated with 3 Gy of gamma irradiation and less after a 6-Gy dose (47.5 and 18.2\%, respectively, compared with unirradiated controls) (Fig. 1). The volume of gastric secretion was also higher in 3- or 6Gy irradiated rats compared with their unirradiated counterparts $(5.2 \pm 0.4,6.7 \pm 0.5$ vs. $7.1 \pm 0.7 \mathrm{ml} 100$ g/4 h).

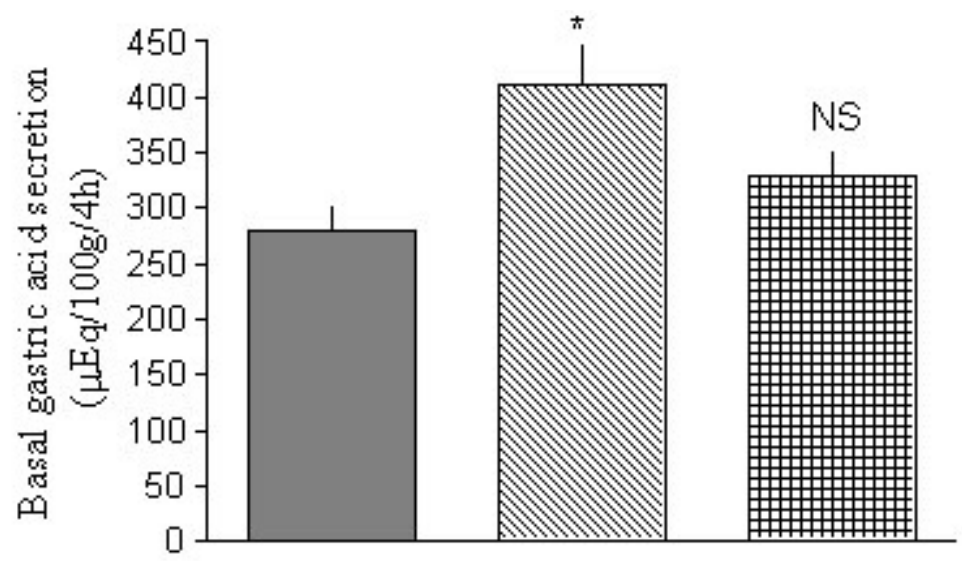

$\square$ Unirradiated control

\$1⿴囗十 3 Gy gamma-irradiated rats

曲 6 Gy gamma-irradiated rats

FIGURE 1. Effect of gamma irradiation on basal (nonstimulated) gastric acid secretion in the 4-h pylorus-ligated rat. Rats were subjected to 3- or 6-Gy gamma irradiation and 7 days later subjected to pylorus ligation together with i.g. 2 ml of physiological saline for 4 h. ${ }^{*} p<0.05$; NS: not significant vs. control (unirradiated group).

\section{Gastric Mucus}

Gastric mucus indicated by alcian blue dye recovery was reduced by 8.2 and $16.7 \%$ in 3- or 6-Gy gamma irradiated rats compared to unirradiated rats (121.6 \pm 8.6 and $110.3 \pm 10.8$ vs. $132.4 \pm 10.6 \mu \mathrm{g} / \mathrm{g})$.

\section{Pentagastrin-Stimulated Gastric Acid Secretion}

Gastric acid secretion in the 4-h pylorus-ligated control (unirradiated) rats given pentagastrin (150 $\mu \mathrm{g} / \mathrm{kg}$ ) was $293.5 \pm 22 \mu \mathrm{Eq} / 4 \mathrm{~h} / 100 \mathrm{~g}$. On the other hand, in rats irradiated with 3- or 6-Gy fraction, gastric acid output on the 4-h pylorus-ligated rat following pentagastrin stimulation was markedly decreased by 67.4 and $72.8 \%$, compared with unirradiated controls (Fig. 2).

\section{Histamine-Stimulated Gastric Acid Secretion}

Under the condition of histamine $(1 \mathrm{mg} / \mathrm{kg})$ stimulation, gastric acid output in those irradiated with 3- or 6-Gy fraction of gamma rays was markedly lower (by 47 and 62.8\%) than that in unirradiated rats (136.9 \pm 13.3 and $115.7 \pm 9.7$ vs. $311.4 \pm 19.6 \mu \mathrm{Eq} / 100 \mathrm{~g} / 4 \mathrm{~h}$, respectively) (Fig. 3).

Histological examination of sections of rat gastric mucosa indicated superficial mucosal injury, although engorgement of microvessels with erythrocytes and some exfoliation of cells was seen in irradiated rats after stimulation with pentagastrin or histamine (Fig. 4). 


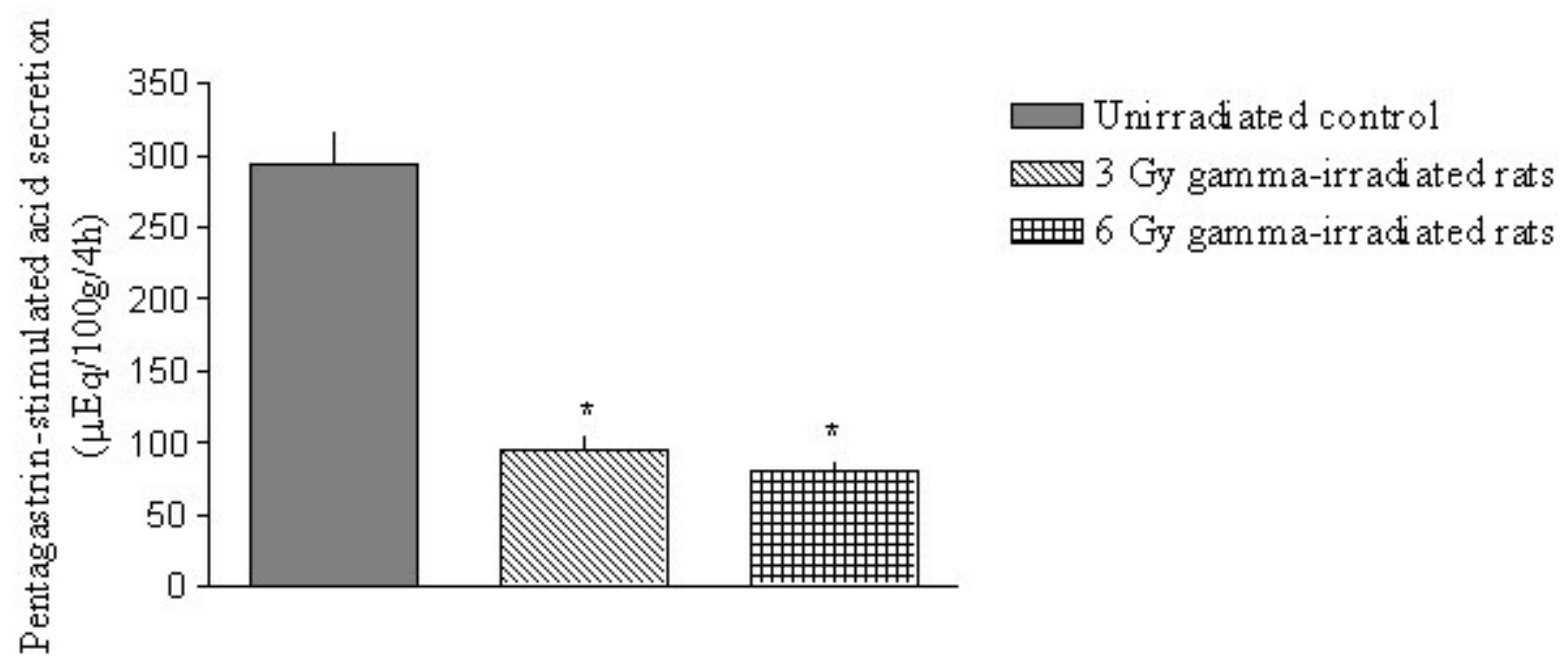

FIGURE 2. Effect of gamma irradiation on pentagastrin $(150 \mu \mathrm{g} / \mathrm{kg})$-stimulated gastric acid secretion in the 4-h pylorus-ligated rat. Rats were subjected to 3- or 6-Gy gamma irradiation and 7 days later subjected to pylorus ligation and s.c. pentagastrin together with i.g. $2 \mathrm{ml}$ of physiological saline for $4 \mathrm{~h} .{ }^{*} p<0.05$ vs. control (unirradiated group).

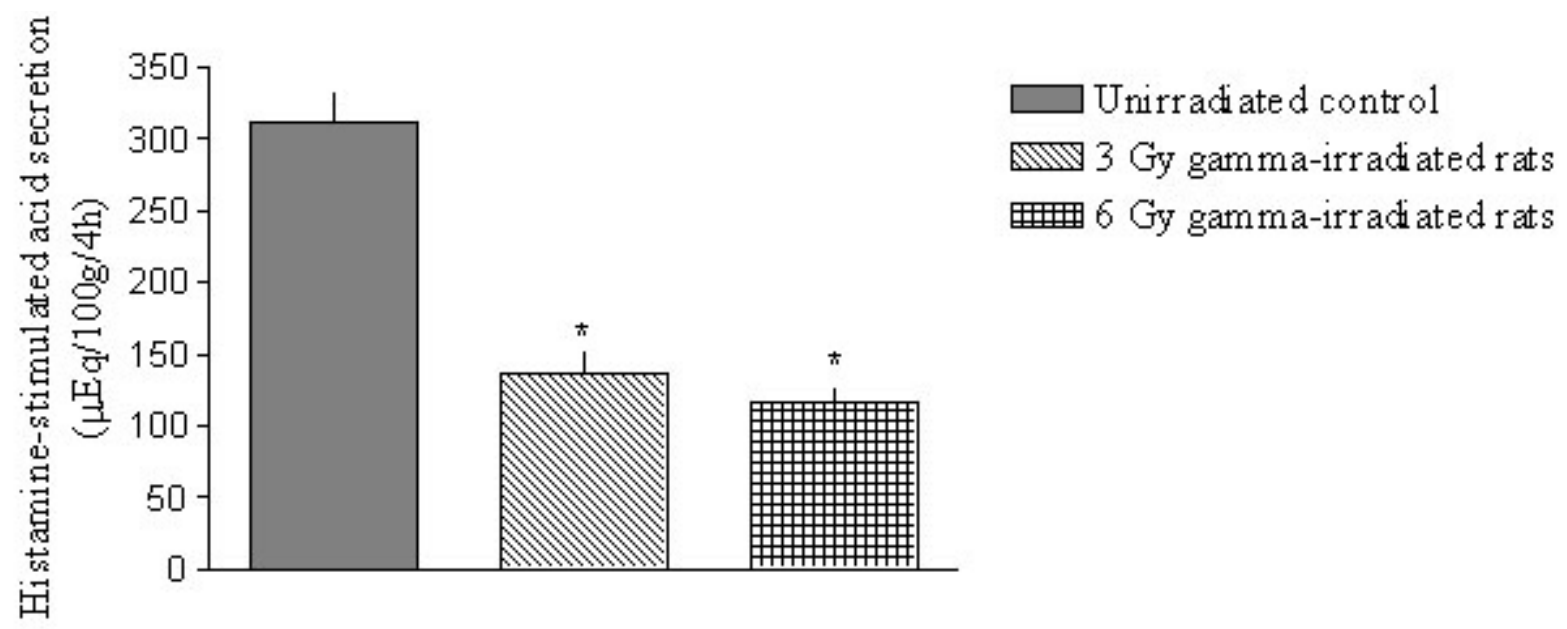

FIGURE 3. Effect of gamma irradiation on histamine $(1 \mathrm{mg} / \mathrm{kg})$-stimulated gastric acid secretion in the 4-h pylorus-ligated rat. Rats were subjected to 3- or 6-Gy gamma irradiation and 7 days later subjected to pylorus ligation and s.c. histamine together with i.g. $2 \mathrm{ml}$ of physiological saline for $4 \mathrm{~h}$. ${ }^{*} p<0.05$ vs. control (unirradiated group).

\section{Gastric Ulcer Studies}

Both the number and severity of gastric mucosal lesions caused by indomethacin were markedly increased after 3- or 6-Gy irradition; the effect being dose dependent. Further, gastric acid output was reduced by 22 and 54.7\% in rats irradiated with 3- or 6-Gy fraction (273.8 \pm 26.7 and $159.2 \pm 12.7$ $\mu \mathrm{Eq} / 100 \mathrm{~g} / 4 \mathrm{~h}$ ) as compared with unirradiated controls (351.2 $\pm 19.6 \mu \mathrm{Eq} / 100 \mathrm{~g} / 4 \mathrm{~h})$. The volume of gastric secretion was decreased in 3- or 6-Gy irradiated rats compared with their unirradiated counterparts $(5.1 \pm 0.4,5.2 \pm 0.5$ vs. $6.4 \pm 0.3 \mathrm{ml} / 100 \mathrm{~g} / 4 \mathrm{~h})$. Similarly, prior exposure to 3- or 6-Gy gamma irradiation exacerbated the degree of gastric mucosal injury caused by $50 \%$ ethanol in a dose-dependant manner (Table 1). 


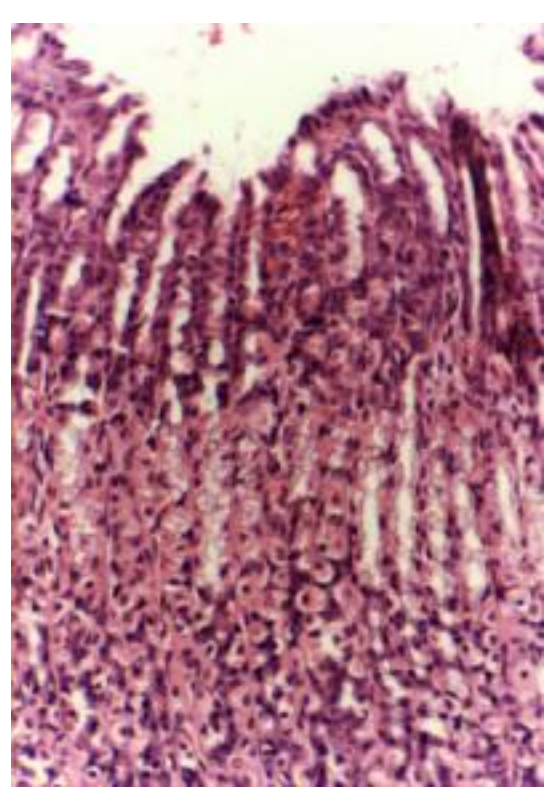

A

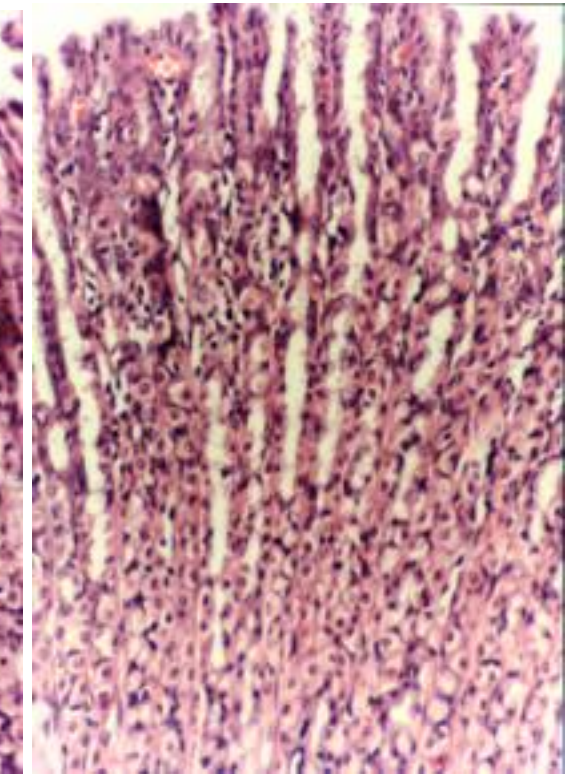

B

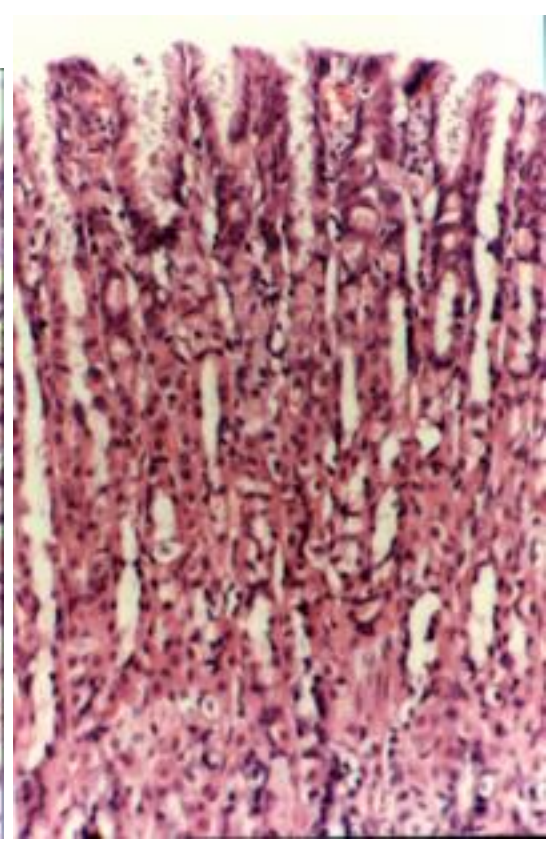

C

FIGURE 4. Photomicrograph of gastric mucosa from whole-body gamma-irradiated rats subjected to pylorus ligation and $2 \mathrm{ml}$ of orogastric $0.9 \%$ saline for $4 \mathrm{~h}$; (A) control saline, (B) pentagstrin treated, (C) histamine treated. The mucosa shows minimal superficial injury and engorgement of microvessels with erythrocytes; changes being most marked after pentagastrin or histamine stimulation (H \& E stain).

TABLE 1

Effect of a Single Dose (3 or 6 Gy) Whole-Body Gamma Irradiation on the Indomethacinand Ethanol-Induced Gastric Mucosal Damage in 4-h Pylorus-Ligated Rats

\begin{tabular}{|c|c|c|c|c|}
\hline Group & $\begin{array}{c}\text { Number of } \\
\text { Lesions/Rat/4 h }\end{array}$ & $\begin{array}{c}\text { Severity of } \\
\text { Lesions/Rat/4 h }\end{array}$ & $\begin{array}{c}\text { Gastric } \\
\text { Secretory } \\
\text { Volume } \\
(\mathrm{ml} / 100 \mathrm{~g} / 4 \mathrm{~h})\end{array}$ & $\begin{array}{l}\text { Gastric Acid } \\
\text { Output } \\
(\mu \mathrm{Eq} / 100 \mathrm{~g} / 4 \mathrm{~h})\end{array}$ \\
\hline IND control & $1.8 \pm 0.5$ & $3.8 \pm 1.2$ & $6.4 \pm 0.3$ & $351.2 \pm 26.7$ \\
\hline + $3 \mathrm{~Gy}$ & $2.4 \pm 0.4^{*}$ & $4.1 \pm 0.7^{*}$ & $5.1 \pm 0.4^{*}$ & $273.8 \pm 23.3^{*}$ \\
\hline+6 Gy & $4.7 \pm 1.3^{\mathrm{NS}}$ & $7.8 \pm 1.7^{*}$ & $5.2 \pm 0.3^{\star}$ & $159.2 \pm 12.7^{*}$ \\
\hline Eth control & $4.0 \pm 0.9$ & $7.2 \pm 1.7$ & $2.5 \pm 0.2$ & $28.5 \pm 3.9$ \\
\hline + $3 \mathrm{~Gy}$ & $7.7 \pm 1.5^{\star}$ & $14.8 \pm 2.2^{*}$ & $2.9 \pm 0.2^{\mathrm{NS}}$ & $35.7 \pm 4.6^{\mathrm{NS}}$ \\
\hline+6 Gy & $12.8 \pm 0.3^{\star}$ & $36.3 \pm 3.4^{*}$ & $2.9 \pm 0.1^{\mathrm{NS}}$ & $32.3 \pm 3.7^{\mathrm{NS}}$ \\
\hline
\end{tabular}

Abbreviations: IND, indomethacin; Eth, ethanol. Statistical differences between control (unirradiated) and treatment (irradiated) groups were tested using one-way ANOVA and Duncan's multiple range test. A value of $p<0.05$ was considered statistically significant. ${ }^{\star} p<0.05$; NS: not significant vs. control group.

\section{DISCUSSION}

Data obtained in the present study from 3- or 6-Gy whole-body gamma-irradiated rats indicate that a significant increase in gastric acid secretion is registered in rats on the $7^{\text {th }}$ day postirradiation. Under pentagastrin or histamine stimulation, however, gastric acid secretion in rats irradiated with 3-Gy fraction 
did not change, whereas those irradiated with 6-Gy fraction showed significantly lower acid output than unirradiated rats.

Studies indicated that exposure to irradiation could suppress gastric acid secretion. In man, decrease in gastric acid secretion was registered 10-14 days after irradiation of the lumbar area. Acid production indices came back to normal 3-3.5 months after irradiation[11]. Vaughan et al.[4] noted in anesthetized, acute gastric fistula rats a transient inhibition of spontaneous (nonstimulated) gastric acid secretion immediately after a dose of 240 R (2.4 Gy), whole-body X-ray irradiation, which resumed promptly after gastrin injection. In addition, gastrin-stimulated acid secretion was inhibited after a dose of 600 or $1200 \mathrm{R}$ (6 or 12 Gy) X-ray irradiation. Man et al.[5] irradiated mice stomachs with 9-Gy X-rays and observed that under pentagastrin stimulation $(62.5 \mu \mathrm{g} / \mathrm{kg})$, acid and histamine secretion was significantly lower than that of the unirradiated controls 7 days after gastric irradiation. It was postulated that depletion of gastric histamine store contributes to the reduction in acid production, for in mice exposed to a single dose of 9 or 15 Gy of X-rays directed to the stomach, mean gastric mural histamine fell to 61 and $46 \% 7$ days after irradiation[12]. In guinea pigs, total-body irradiation with $400 \mathrm{~Gy}$ suppressed gastric acid secretion under basal conditions and during histamine stimulation by $50-90 \%$. Recovery from the radiation damage was only partial after 1 week[6]. In dogs, a decrease of $\mathrm{H}^{+}$production in the gastric juice was seen during the first 7 days after 12.7-Gy abdominal X-ray irradiation[13]. In rhesus monkeys, inhibition of gastric acid was evident for $2 \mathrm{~h}$ after total body exposure to $800-\mathrm{cGy}{ }^{60} \mathrm{Co}$ but returned to preirradiation levels 2 days later. Irradiation produced an immediate significant increase in gastric juice concentration of PGE2 and PGI2 by 64.5 and $50.4 \%$, respectively, which might have accounted for the radiation-induced suppression of acid output[14]. More recently, however, Lehy et al.[7] observed in awake gastric fistula rats an increase in basal acid secretion and plasma gastrin in rats at 3 and 7 days after exposure to 2- or 6-Gy single fraction gamma irradiation. Our data in pylorus-ligated rats are in agreement with those reported by Lehy and co-workers[7] and suggest that lower doses of irradiation are associated with increase in basal (nonstimulated) gastric acid secretion. The discrepancies in the literature regarding the effect of irradiation on gastric acid secretion are likely to arise from varying conditions, varying species, and different methods for assaying gastric acid output, and are much more likely to result from the variability in the doses of irradiation used. With higher doses of irradiation, the acute inflammatory response[1,2,15], impaired mucosal microcirculation[15], luminal release of prostaglandins[14], depletion of gastric histamine[5,12], as well as decrease of ATPase activity[13] are likely to account for the inhibition of gastric acid secretion observed in man and in acute animal experiments.

Although an increase in circulating gastrin by low doses of gamma irradiation[7] or sensitization to acetylcholine and histamine[16] might provide an explanation for the observed increase in acid output under basal conditions, the same mechanism cannot explain the opposite effect of irradiation on stimulated gastric acid secretion. The finding in the present study of a decrease in gastric acid output under pentagastrin or histamine stimulation and also after indomethacin in rats exposed to irradiation, could represent at least in part an increased permeability of an already-breached gastric mucosal barrier and enhanced $\mathrm{H}^{+}$back diffusion following the secretagogues or the ulcerogenic agent indomethacin.

The pylorus-ligated rat is a widely used model for the assay of gastric acid secretion, which permits the determination of gastric acid secretion within a defined period of time[17]. The hypersecretion of the pylorus-ligated rat is dependent on vagal activity being mediated by long vago-vagal reflexes for it can be abolished by vagotomy or atropine. Following the initial phase of hypersecretion of acid with the maximum volume and acid output reaching it maximum after $5-6 \mathrm{~h}$, acid production ceases and actually diminishes $12-20 \mathrm{~h}$ after ligation[18,19,20], which is likely to be the result of depletion of energy stores and/or increased mucosal permeability. Vallgren and co-workers[21] suggested that both vago-vagal and intramural reflexes involve a cholinergic and histaminergic pathway that does not involve histamine derived from the gastric endocrine-like cells. Andersson et al.[22] further indicated that unlike pentagastrin stimulation, vagally stimulated gastric acid secretion induced by pylorus ligation was unaffected by depletion of histamine from the entrochromaffin-like cells [ECL] with alphafluoromethylhistidine. Ultrastructural studies by Zhao and co-workers[23] confirmed that ECL in the rat oxyntic mucosa do not mediate the gastric acid response to pylorus ligation, and that ECL cells in the 
pylorus-ligated stomach retain their ability to respond to gastrin with activation. Since histamine-forming capacity is markedly reduced in the stomachs of mice subjected to irradiation[12], it is thus possible that the present findings represent failure of the secretagogue (histamine or pentagastrin)-direct stimulation of parietal cell. This hypothesis assumes that direct stimulation of the parietal cell with histamine or pentagastrin overrides the reflexes caused by ligating the pylorus and that mucosal histamine plays a more important role in the action of gastrin than of cholinomimetics or pylorus ligation on the parietal cell, which has been suggested by different workers[21,22,24].

A likely explanation for the failure of the secretagogue (histamine or pentagastrin)-direct stimulation of parietal cell may be the decrease of adenosine triphosphatase (ATPase) activity[13] and the depletion of energy stores. The metabolic activity of the gastric mucosa is very high, owing mainly to the secretion of acid by parietal cells[25]. The secretion of $\mathrm{HCl}$ is an energy-demanding process, which is partly given by the transformation of adenosine triphosphate (ATP) into adenosine diphosphate (ADP) in the gastric mucosa, catalyzed by the membrane-bound ATPase. This transformation is facilitated by the effect of acetylcholine chloride on the transport ATPase system. This effect of acetylcholine chloride is prevented by atropine [26, 27, 28]. Irradiation alone can inhibit the metabolism of gastric cells and tissues. The activity of total ATP-ase and Mg-dependent ATP-ase in gastric mucosal cells is reduced shortly after irradiation $[13,29]$. ATP plays a fundamental role in radioprotection and metabolic provision for repair processes [30]. Survival of the mice, using 30 days post-irradiation as the endpoint, was increased from $40 \%$ to $85 \%$ by action of the exogenous ATP [31, 32].

The absence of marked gastric mucosal injury in the stomachs of irradiated rats stimulated with histamine or pentagastrin compared with those treated with indomethacin may be due to increased blood flow in the former situation[33,34], which helps to neutralize the influxing acid load and supplies energy substrates and oxygen, thereby helping the gastric mucosa to resist the chemical injury. This crucial role of gastric mucosal blood flow in maintaining gastric mucosal integrity has been demonstrated in many studies[35,36,37,38,39].

In the case of damage to the gastric mucosa by ethanol, pentagastrin and histamine, while stimulating acid secretion, were able to reduce gastric mucosal damage due to ethanol[26]. Increase in metabolic activity by pentagastrin and histamine help to prevent the chemical-induced injury to the gastric mucosa[26]. It has been shown that the actively secreting gastric mucosa has an increased resistance to noxious chemical injury[26,40]. Conversely, after irradiation and due to depletion of energy stores, the mucosal damage due to chemical injury is likely to be exacerbated, as can be seen in the present study, where damage due to ethanol or indomethacin is intensified in rats subjected to irradiation. Changes in gastric mucus can alter the susceptibility of the gastric mucosa to injury[41]. A reduction in gastric mucus by irradiation shown in the present work may be an additional mechanism by which irradiation enhanced the indomethacin and ethanol damage to gastric mucosa.

\section{REFERENCES}

1. Breiter, N., Trott, K.R., and Sassy, T. (1989) Effect of X-irradiation on the stomach of the rat. Int. J. Radiat. Oncol. Biol. Phys. 17, 779-784.

2. Breiter, N., Sassy, T., and Trott, K.R. (1993) The effect of dose fractionation on radiation injury in the rat stomach. Radiother. Oncol. 27, 223-228.

3. Yeoh, E., Horowitz, M., Russo, A., Muecke, T., Robb, T., Maddox, A., and Chatterton, B. (1993) Effect of pelvic irradiation on gastrointestinal function: a prospective longitudinal study. Am. J. Med. 95, 397-406.

4. Vaughan, B.E., Cummins, J.T., and Pessotti, R.L. (1971) X-ray inhibition of gastrin-stimulated acid secretion in relation to mucosal activity of $(\mathrm{Na}+, \mathrm{K}+)$-dependent ATPase. Radiat. Res. 48, 508-517.

5. Man, W.K., Gompertz, R.H., Li, S.K., Michalowski, A., Baron, J.H., and Spencer, J. (1988) Effect of gastric irradiation on gastric secretion and histamine in mice. Agents Actions 23, 297-299.

6. Batzri, S. and Catravas, G. (1988) Inhibition of gastric secretion in guinea pig by relatively low dose ionizing radiation. Proc. Soc. Exp. Biol. Med. 189, 255-260.

7. Lehy, T., Dessirier, V., Attoub, S., Bado, A., Griffiths, N.M., and Linard, C. (1998) Exposure to ionizing radiation modifies circulating gastrin levels and gastrointestinal endocrine cell densities in the rat. Int. J. Radiat. Biol. 73, 331340 . 
8. Shay, H., Komarov, S.A., Fels, S.S., Meranze, D., Gruenstein, M., and Siplet, H. (1945) A simple method for the uniform production of gastric ulceration in the rat. Gastroenterology 5, 43-61.

9. Mózsik, G., Morón, F., and Jávor, T. (1982) Cellular mechanisms of the development of gastric mucosal damage and of gastroprotection induced by prostacyclin in rats. A pharmacological study. Prostaglandins Leukot Med. 9, 71-84.

10. Corne, S.J., Morrissey, S.M., and Woods, R.J. (1974) A method for the quantitative estimation of gastric mucosal barrier. J. Physiol. 242, 116P-117P.

11. Lobanova, E.A., Vermel, A.E., and Balter, S.A. (1981) Morphofunctional characteristics of the gastric mucosa in subacute local irradiation of the lumbar-aortic region in lymphogranulomatosis. Vopr. Onkol. 27, 31-34.

12. Man, W.K., Li, S.K., Spencer, J., Baron, J.H., and Michalowski, A.S. (1990) Gastrointestinal histamine and histamine formation capacity after gastric irradiation in mice. Br. J. Radiol. 63, 209-213.

13. Polozy, E.A., Kostesa, N.J., and Basirova, S.A. (1989) Mechanisms of the inhibition of the functional activity of the stomach in acute radiation sickness. Radiobiol. Radiother. (Berl.) 30, 151-156.

14. Dubois, A., Dorval, E.D., Steel, L., Fiala, N.P., and Conklin, J.J. (1987) Effect of ionizing radiation on prostaglandins and gastric secretion in rhesus monkeys. Radiat. Res. 110, 289-293.

15. Buell, M.G. and Harding, R.K. (1989) Proinflammatory effects of local abdominal irradiation on rat gastrointestinal tract. Dig. Dis. Sci. 34, 390-399.

16. Jankovi, S.M., Matovi, M., Milaranovi, D., and Igrutinovi, I. (1996) Sensitization of rat gastrointestinal tract to acetylcholine and histamine produced by X-radiation. Acta Physiol. Hung. 85, 215-230.

17. Robert, A., Nezamis, J.E., Lancaster, C., and Hanchar, A.J. (1979) Cytoprotection by prostaglandins in rats. Prevention of gastric necrosis produced by alcohol, $\mathrm{HCl}, \mathrm{NaOH}$, hypertonic $\mathrm{NaCl}$ and thermal injury. Gastroenterology 77, 433-443.

18. Mózsik, G. and Vizi, F. (1976) Examination of stomach wall $\mathrm{Mg}^{+2}-\mathrm{Na}^{+}-\mathrm{K}^{+}$-dependent ATPase, ATP, and ADP in pylorus-ligated rats. Am. J. Dig. Dis. 21, 649-654.

19. Hakanson, R., Hedenbro, J., Liedberg, G., Sundler, F., and Vallgren, S. (1980) Mechanisms of gastric acid secretion after pylorus and oesophagus ligation in the rat. J. Physiol. 305, 139-149. Mózsik, Gy., Beck, Z., Füzesi, Z., Kiss, J., Nagy, L., Palotai, Z., Szilágyi, J., Tárnok, F., Tóth, E., Vizi, F. (1978) Cellular mechanisms of gastric hypersecretion in pylorus-ligated rats. Acta. Physiol. Scand. (special suppl), 187-198.

21. Vallgren, S., El-Munshid, H.A., Hedenbro, J., Rehfeld, J.F., and Hakanson, R. (1983) Mechanism of gastric acid response to pylorus ligation: effects of nephrectomy. Scand. J. Gastroenterol. 18, 491-496.

22. Andersson, K., Cabero, J.L., Mattsson, H., and Hakanson, R. (1996) Gastric acid secretion after depletion of enterochromaffin-like cell histamine. A study with alpha-fluoromethylhistidine in rats. Scand. J. Gastroenterol. 31, 24-30.

23. Zhao, C.M., Chen, D., Monstein, H.J., Ding, X.Q., Sundler, F., and Hakanson, R. (1996) Rat stomach enterochromaffin-like cells are not stimulated by pylorus ligation. A biochemical and ultrastructural study. Scand. J. Gastroenterol. 31, 31-37.

24. Main, I.H. and Pearce, J.B. (1982) Increased histamine-output from the isolated gastric mucosa of the rat in response to pentagastrin and methacholine. Br. J. Pharmacol. 76, 51-59.

Aase, S., Dahl, E., Roland, M., and Hars, R. (1983) Morphometric studies of parietal cells during basal conditions and during stimulation with pentagastrin in healthy subjects. Scand. J. Gastroenterol. 18, 913-923. Mózsik, G. and Jávor, T. (1988) A biochemical and pharmacological approach to the genesis of ulcer disease. I. A model study of ethanol-induced injury to gastric mucosa in rats. Dig. Dis. Sci. 33, 92-105. Mózsik., G. (1985) Molecular and biochemical aspects of peptic ulcer disease. Dig. Dis. Sci. 30, 390.

28. Mózsik, G., Nagy, L., Kutas, J., and Tárnok, F. (1974) Interaction of cholinergic function with Mg2 $2^{+}-\mathrm{Na}^{+}-\mathrm{K}^{+}-\mathrm{dependent}$ ATP-ase system of cells in the human fundic gastric mucosa. Scand. J. Gastroenterol. 9, 741-745.

29. Groza, P., Gheorghe, N., and Stefan, M. (1973) Studies of the effect of irradiation on gastric secretion in the rat and the radioprotective effect of ATP. Rev. Roum. Physiol. 10, 3-11.

30. Szeinfeld, D., de-Villiers, N. (1993) Cholinesterase response in the rhabdomyosarcoma tumor and small intestine of the BALB/c mice and the radioprotective actions of exogenous ATP after lethal dose of neutron radiation.

Strahlenther. Onkol. 169, 311-316.

31. Szeinfeld, D. (1990) The multifactorial role of ATP in repair processes and radioprotection. Med. Hypotheses 32, 225-229.

Szeinfeld, D. and de-Villiers, N. (1992) Response of normal BALB/c mouse tissue to p(66 MeV)/Be fast neutron radiation: protection by exogenous ATP. Strahlenther. Onkol. 168, 174-178.

33. Pique, J.M., Leung, F.W., Tan, H.W., Livingston, E., Scremin, O.U., and Guth, P.H. (1988) Gastric mucosal blood flow response to stimulation and inhibition of acid secretion. Gastroenterology 95, 642-650.

34. Holm, L. and Jagare, A. (1994) Histamine is not involved in pentagastrin-induced gastric mucosal vasodilation in the rat. Am. J. Physiol. 266, G55-61.

Starlinger, M., Schiessel, R., Hung, C.R., and Silen, W. (1981) $\mathrm{H}^{+}$back diffusion stimulating gastric mucosal blood flow in the rabbit fundus. Surgery $\mathbf{8 9}, 232-236$.

36. Kiviluto, T., Voipio, J., and Kivilaakso, E. (1988) Subepithelial tissue pH of rat gastric mucosa exposed to luminal acid, barrier breaking agents, and haemorrhagic shock. Gastroenterology 94, 695-702.

37. Howard, T.J., Passaro, E., Jr., and Guth, P.H. (1993) Isoproterenol prevents ethanol-induced microcirculatory stasis 
and deep histologic injury in rat gastric mucosa. Dig. Dis. Sci. 38, 1201-1209.

38. Abdel-Salam, O.M.E., Szolcsányi, J., Porszász, R., and Mózsik, G. (1996) Effect of capsaicin and resiniferatoxin on gastrointestinal blood flow in rats. Eur. J. Pharmacol. 305, 127-136.

39. Abdel-Salam, O.M.E., Mózsik, Gy., and Szolcsányi, J. (1997) The effect of intragastric capsaicin and resiniferatoxin on the indomethacin-induced gastric mucosal damage in rats. In Cell Injury and Protection in Gastrointestinal Tract: From Basic Science to Clinical Perspectives. Mózsik, Gy., Nagy, L., Pár, A., and Rainsford, K.D., Eds. Kluwer Academic, Dordrecht. pp. 95-105.

40. O'Brien, P.E. and Carter, D.C. (1977) Effect of gastric secretory inhibitors on the gastric mucosal barrier. Gut 16, 437442.

41. Shea-Donohue, T., Danquechin-Dorval, E., Montcalm, E., El-Bayar, H., Durakovic, A., Conklin, J.J., and Dubois, A. (1985) Alterations in gastric mucus secretion in rhesus monkeys after exposure to ionizing radiation. Gastroenterology 88, 685-690.

\section{This article should be referenced as follows:}

Abdel Salam, O.M.E., Hadajat, I., Ragab Bayomy, A., El-Shinawy, S., and Arbid, M.S. (2005) Acute effect of gamma irradiation on gastric acid secretion and gastric mucosal integrity in the rat. TheScientificWorldJOURNAL 5, 195-204.

\section{Handling Editor:}

J. Chamberlain, Principal Editor for Pharmaceutical Sciences — a domain of TheScientificWorldJOURNAL. 


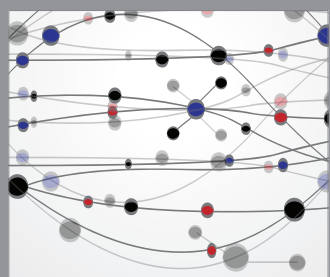

The Scientific World Journal
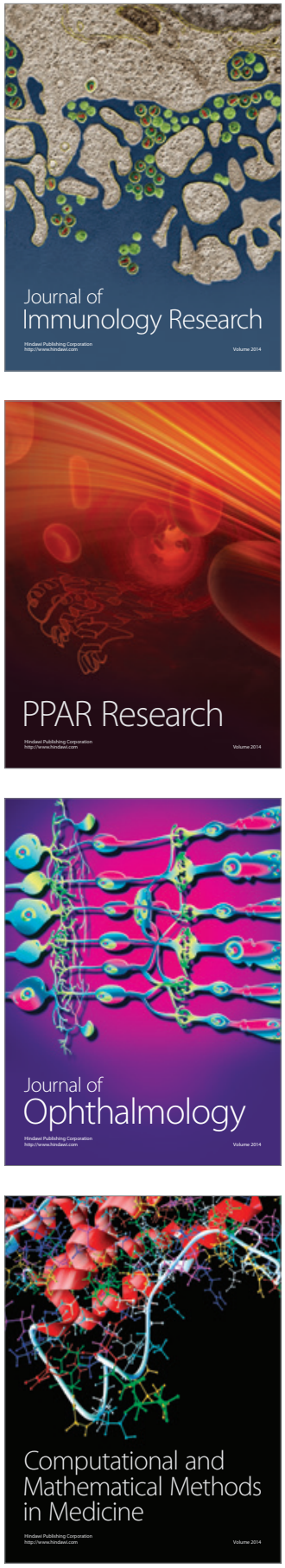

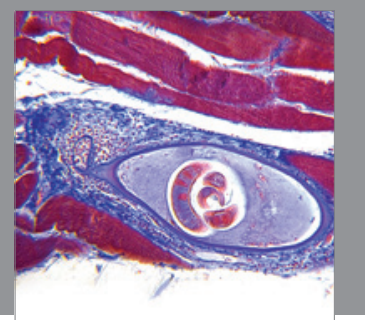

Gastroenterology

Research and Practice
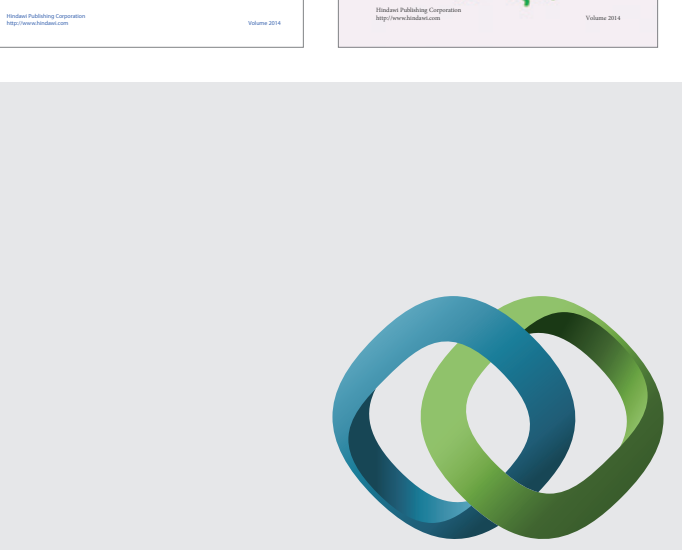

\section{Hindawi}

Submit your manuscripts at

http://www.hindawi.com
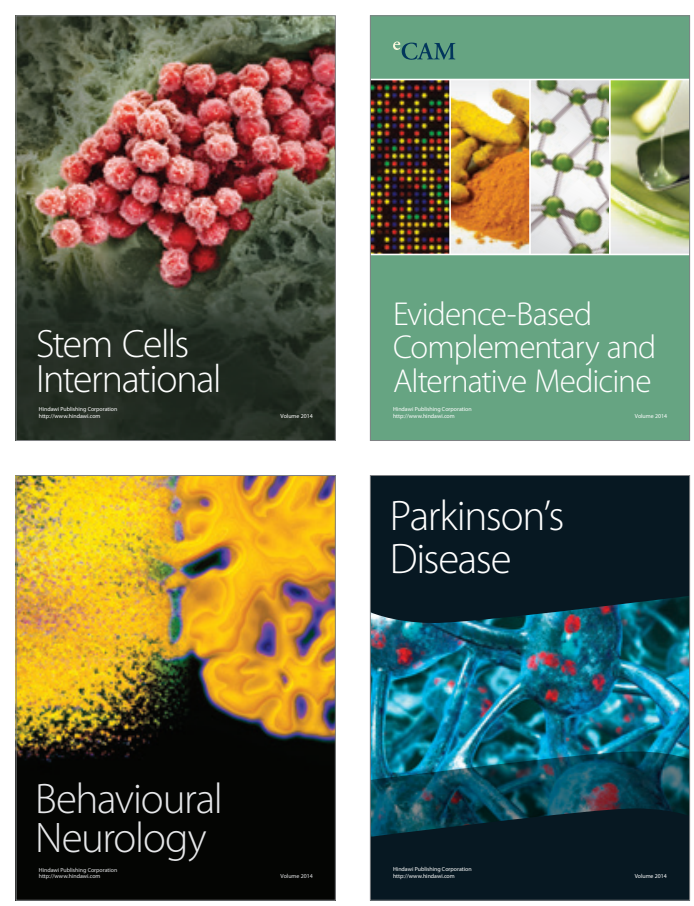

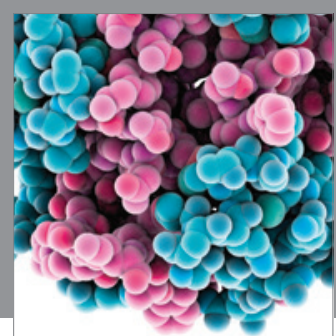

Journal of
Diabetes Research

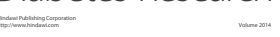

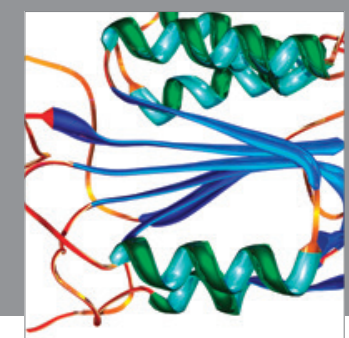

Disease Markers
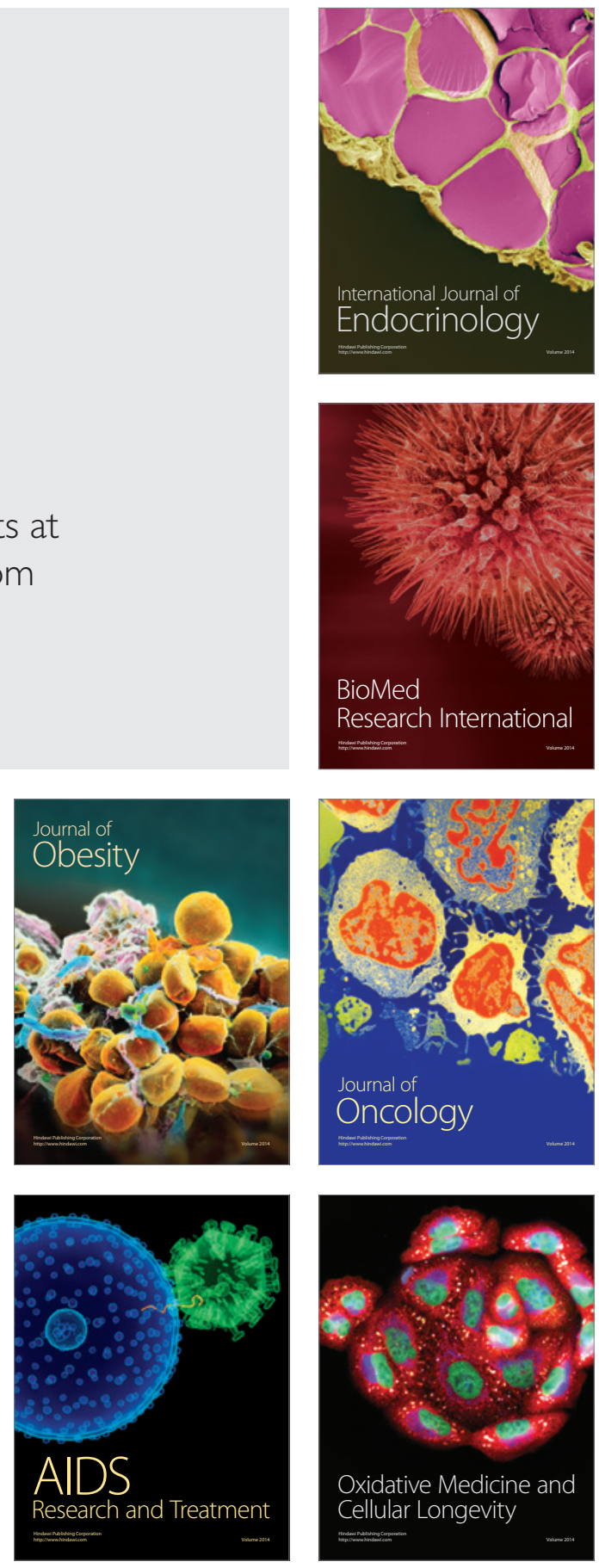